\title{
Response of Acacia tortilis to Elephant Browsing in Tarangire National Park, Tanzania: Possible Above-Ground Compensation?
}

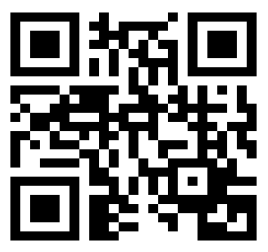

\author{
Joanne E. Johnson ${ }^{1,2 *}$ \& James J. Ebersole ${ }^{2,3}$
}

Large herbivore browsing leads to above-ground compensatory growth for some species of Acacia trees, but strength and variation of the relationship are poorly understood. Acacia tortilis is a keystone species in East African savannas and experiences a wide range of browsing pressure. In this study, terminal bud scale scars were used to measure yearly shoot elongation in A. tortilis experiencing various levels of elephant browsing at three mesic sites in northern Tarangire National Park, Tanzania. For all four years of growth, twig elongation remained very similar across elephant browsing pressure from minimal to heavy. Although never significant, twig elongation in 2013, 2011 and 2010 was somewhat higher in trees experiencing moderate elephant browsing pressure, suggesting a possible tendency toward compensatory growth. However, growth in 2012 had a slight negative correlation with browsing pressure. Further research can test whether A. tortilis compensates for moderate elephant browsing by elongating twigs more and if that growth slows slightly at higher browsing pressure. Overall $A$. tortilis tolerates elephant browsing extraordinarily well, but because the elephant population in Tarangire National Park is large and growing, managers should continue to monitor this keystone for decreased growth and tree mortality.

\section{INTRODUCTION}

Woody plants provide energy and nutrients for many mammals in African savannas. Throughout Africa, Acacia spp. trees provide the primary food source for numerous browsers, and also serve as important habitat for birds (Dharani, Kinyamario, Wagacha \& Rodrigues, 2009). Many species, including black rhinoceros, giraffe, grey duiker, dik-dik, grysbok, klipspringer, gerenuk, dibatag, bushbuck, and kudu, feed exclusively on woody browse (OwenSmith, 1982). Because Acacia trees fix nitrogen, this also leads to higher forage quality in grasses underneath them compared to areas not under their canopies (Ludwig, De Kroon \& Prins, 2008; Mopipi, Trollope \& Scogings, 2009). Understanding the conditions that allow continued Acacia growth despite browsing will allow conservationists to monitor and prevent mortality of this

${ }^{1}$ Dept. of Biology, Macalester College, 1600 Grand Ave., St. Paul, MN 55105, U.S.A.

${ }^{2}$ Associated Colleges of the Midwest, 11 E. Adams Street, Suite 800, Chicago, IL 60603, Chicago, IL 60603, U.S.A.

${ }^{3}$ Department of Organismic Biology and Ecology, Colorado College, 14 E Cache La Poudre St., Colorado Springs, CO, 80903, U.S.A.

*To whom correspondence should be addressed: joannejohnson021@gmail.com

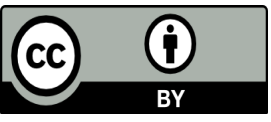

Except where otherwise noted, this work is licensed under https://creativecommons.org/licenses/by/4.0/ doi: $10.22186 /$ jyi.32.1.1-6 keystone savanna species.

There are many variables in woody savanna which affect the productivity of trees, including Acacia spp. Disease decreases growth, rainfall increases growth, and fire has variable effects on growth based on the severity of the fire and the characteristics of various Acacia species (Dharani et al., 2009; Fornara, 2008; Mopipi et al., 2009; Otieno, Kinyamario \& Omenda, 2001; Scogings, Johansson, Hjalten \& Kruger, 2012). However, effects of herbivory and the dynamic interactions between browsers and woody plants have been heavily disputed. Several researchers found that intense large herbivore browsing results in compensatory aboveground plant growth and can lead to alternative stable states (Dublin, Sinclair \& McGlade, 1990; Jachmann \& Bell, 1985; Smallie \& O'Connor, 2000). However, others have found that large herbivore populations, such as elephants (Loxodonta africana) or giraffes (Giraffa camelopardalis), have a negative effect on woody vegetation growth (Guldemond \& Van Aarde, 2008; Chira \& Kinyamario, 2009; Pellew 1984).

Past findings on the effects of browsing on sub-Saharan African Acacia species vary by mammal, tree species and response measurement. Browsing by non-elephant large mammals resulted in compensatory growth, leading to higher stem diameter growth of $A$. xanthophloea (Dharani et al., 2009). Similarly, simulated browsing of A. xanthophloea, A. tortilis, A. hockii (Pellew, 1984) and A. karroo (Stuart-Hill \& Tainton, 1989) resulted in increased shoot growth and competitive ability when defoliation rates were between 25-50\%. Du Toit, Bryant \& Frisby (1990) and Chira \& Kinyamario (2009) respectively found that heavy browsing by elephants led to an increase in shoot growth and higher nitrogen concentration in A. nigrescens foliage and coppice growth in $A$. 
brevispica. Conversely, Gandiwa, Magwati, Zisadza, Chinuwo, \& Tafangenyasha (2011) found that South African A. tortilis with moderate to high levels of elephant browsing had smaller mean tree density, height, and basal area, compared to trees with low level of browsing. While recent patterns in precipitation, defoliating insects, disease, and soil fertility can also affect above-ground growth, current evidence suggests that compensatory growth responses occur only under certain levels of browsing pressure before tree mortality and/or resource depletion occurs.

Although compensatory growth in response to browsing has been observed in many Acacia species, the mechanism(s) and evolutionary trade-offs have been heavily disputed. Du Toit et al. (1990) found lower levels of tannins - naturally occurring plant polyphenols that discourage herbivore browsing by lowering metabolic efficiency (Chung, Wong, Wei, Huang \& Lin, 1998) - and higher nitrogen and phosphorus content in heavily browsed $\mathrm{A}$. $\mathrm{ni}$ grescens. They concluded that there is a tradeoff between shoot growth and defensive allo-chemicals for the species. The subsequent increase in palatability would lead to increased browsing, and create a positive feedback loop leading to the evolutionary development of Acacia compensatory growth as a necessary mechanism for the tree survival. Similarly, Fornara \& du Toit (2007) found an inverse relationship between Acacia tolerance (regrowth abilities) and reproduction (seeds produced) in response to browsing, suggesting that above-ground growth came as a trade off with reproduction. Dharani et al. (2009) also observed increased browsing tolerance of $A$. xanthophloea after browsing. However, the study found that compensatory growth was limited to plant stems, while browsing still had a negative effect on tree height and canopy growth. They concluded that trees reallocated resources from leaves to stems and roots. Fornara (2008) similarly found that large herbivore pruning of $A$. nigrescens contributed to enhanced root size and subsequent re-sprouting abilities while negatively impacting maximum tree branch height, suggesting nutrient shunting from foliage to stems and roots.

It has also been hypothesized that the mechanism of shoot growth stimulation after browsing is not a reallocation of nutrients within the individual tree, but increased energy flow from the recycling of nutrients bound in leaf growth (Mopipi et al., 2009). However, Tanentzap \& Coomes (2012) argued that herbivore grazing and browsing lead to decreased terrestrial carbon stock in general, and that the previous theory applies only in environments with sufficient resources to compensate for lost photosynthetic ability of consumed foliage. Other proposed mechanisms relating to resource allocation include: reduced intershoot competition due to woody browse loss, reduced leaf shading enabling enhanced photosynthesis capability, and reduced transpiration allowing more soil water retention (Fornara \& du Toit, 2007; McNaughton, 1979). Numerous studies have resulted in various, sometimes contradictory, evidence and theories for compensatory plant growth mechanisms. Since no general conclusion has been reached, compensatory growth is likely species and location-dependent, influ- enced by browsing type and pressure, nutrient availability, interor intra-species competition, and perhaps other factors.

The mesic Acacia woodland in northern Tarangire National Park is composed largely of $A$. tortilis, one of the most prevalent and widespread Acacia species throughout Africa (Otieno et al. 2001), but has become less dense due to elephant utilization (Tanzania National Parks, 2012). Elephant herbivory can drive vegetation change in savanna ecosystems, and dense elephant populations can lead to over browsing and significant plant mortality (Van Aarde \& Guldemond, 2008). Elephant browsing was found to be a more significant factor than rainfall behind changes in savanna vegetation (Hayward \& Zawadska, 2010). With an average annual growth rate of about $7 \%$ from $1993-2006$, there is no doubt that the Tarangire elephant population has intensified browsing pressure in the area, but it is unclear how the composition and woody plant-browser dynamics of the park savanna have changed (Foley, 2010). If this population growth continues, increased browsing pressure could threaten the survival and resilience of the park's Acacia population.

Understanding the risk of $A$. tortilis decline and growth response to elephant browsing will help reduce tree mortality and prevent the loss of its ecosystem services. In this study, we inferred above-ground compensatory growth if greater growth occurred at moderate levels of branch removal by elephants. We hypothesized that $A$. tortilis trees under moderate levels of elephant browsing will have higher levels of annual shoot elongation because moderate levels of browsing pressure will stimulate more compensatory growth.

\section{METHODS}

\section{Study Site}

Tarangire National Park is located between S03 ${ }^{\circ} 0^{\prime}$ and S03 35 and between $\mathrm{E} 35^{\circ} 45^{\prime}$ and $\mathrm{E} 37^{\circ} 0^{\prime}$ in the Arusha province of northern Tanzania and covers $2,850 \mathrm{~km}^{2}$. As previously described by Ludwig et al. (2008), the park experiences a short rainy season from October to November, and a long rainy season from March to May, with the majority of the $650 \mathrm{~mm} /$ year rainfall occurring between March and April. The park has several major habitat types including Acacia tortilis parkland, tall Acacia woodland dominated by $A$. xanthophloea and $A$. sieberiana, drainage line woodland, and deciduous savanna dominated by Combretum spp. and Commiphora spp. (Ludwig et al., 2008). This study focuses on three mesic sites located in the Lemiyon, Matete and Gursi areas of the northern part of the Park in order to focus on A. tortilis specifically.

\section{Data Collection}

At each of the three sites, we selected five to six trees with little $(<30 \%)$, moderate $(30-50 \%)$, and severe $(>50 \%)$ elephant damage (47 trees total) from trees with multiple accessible unbrowsed twigs to measure. Tree measurements were taken for $A$. tortilis which fit strict criteria $(<200 \mathrm{~m}$ from roads, diameter at breast height $(\mathrm{DBH})>10 \mathrm{~cm}$, and height $>5 \mathrm{~m})$. 
The percentage of canopy removed by elephant browsing was estimated qualitatively to the nearest $10 \%$. Similar manual methods of estimating and quantifying browsing damage on tree canopy were described in Okula \& Sis (1986), Riginos \& Young (2007), Dharani et al. (2009) and Moncrieff (2011). It was not possible to judge the age of tree damage so that some years of measured growth could have occurred before any or some of the recorded damage occurred.

Elongation was measured using terminal bud scale scars on 3-4 twigs for each of the four previous years. We assigned twig measurements to the year in which growth began. To focus on growth response at the tree level, we averaged annual twig measurements within each tree.

Precipitation data to examine differences among years are unfortunately not available from this site, and reproduction occurred after the study time. All data was collected in the park in a short four-week period due to resource limitation.

\section{Data Analysis}

Minitab ver. 17 (Minitab, 2014) was used to test for differences in growth among sites and years using a repeated measures ANOVA with year (fixed factor) crossed with site (random factor) and with trees nested within sites. Before analysis, a square root transformation was used to meet assumptions of normality and equality of variances. For each year linear and quadratic regressions from JMP ver. 11 (JMP $\left.{ }^{\circledR}, 2007\right)$ were used to model relationships between annual shoot elongation and elephant damage. The best model fit was defined as that which had a larger $\mathrm{R}^{2}$ value. Due to the similarity of growth sites we combined them in further analyses and considered all trees independent.

\section{RESULTS}

\section{Consistency of Growth Across Sites}

Twig elongation ranged between $110-240 \mathrm{~mm}$ across the three sites and four years, with the highest average growth recorded for site $\mathrm{A}$ in 2012 and the lowest for site B in 2013 and site A in 2010 (Figure 1). The repeated measures ANOVA showed no differences in twig elongation between growth sites and years. It also measured the effects of an individual tree, and the interaction between site and year (Table 1). While growth year and the mesic site did not affect twig elongation individually ( $p$-values $>.05$ ), the interaction between the two variables was significant $(p=.01)$, as was the variation among trees within sites $(p=.04)$. The repeated measures ANOVA explained $46 \%$ of the variation in annual growth measurements.

\section{Effects of Browsing on Shoot Elongation}

The relationships between elephant browsing damage and annual A. tortilis twig elongation had model $p$-values $>.05$ for all years (Figure 2). For 2013, 2011 and 2010 quadratic regression models were a better fit to the observed data, with higher $\mathrm{R}^{2}$ values (Figure 2 ). The general trend for these years showed that growth at moderate browsing levels (30-60\% damage) was about $20 \mathrm{~mm}$ greater than at low and high levels. For 2012, a linear regression line provided a better fit, showing a very slight $(<5 \mathrm{~mm})$ decrease in shoot

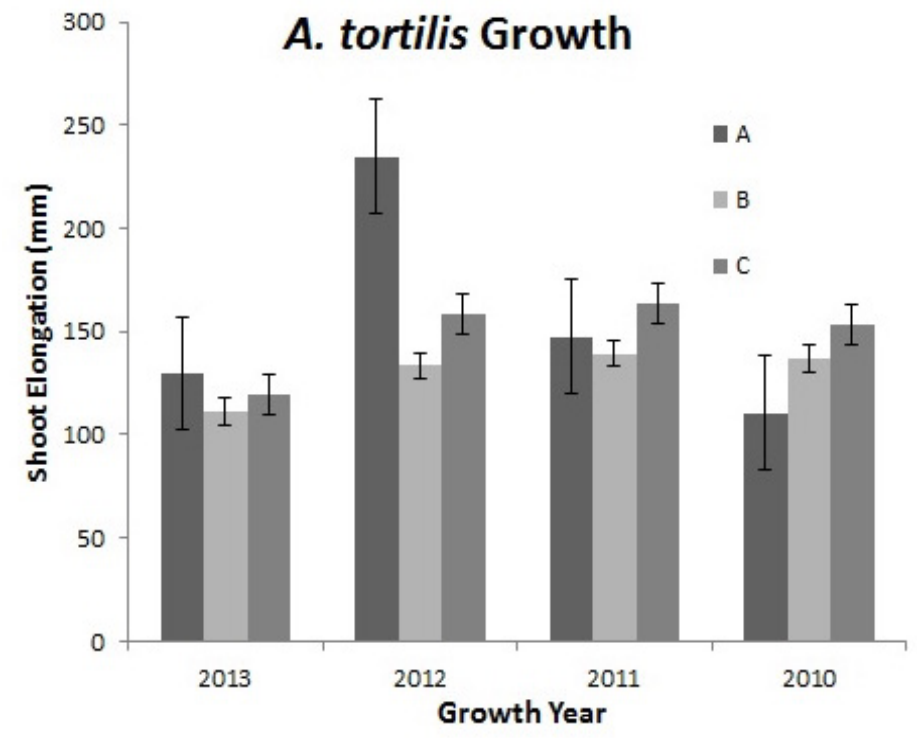

Figure 1. Annual Growth by Site. Variations in growth is represented by mean ( $+\mathrm{SE})$ shoot elongation in A. tortilis, measured using a terminal bud scar scale, at three mesic sites (A, B \& C) in the northern woodlands of Tarangire National Park. Measurements were taken for years 2013, 2012, $2011 \& 2010$.

elongation as browsing pressure increases (Figure 2). Model $\mathrm{R}^{2}$ were low for all relationships, indicating substantial unexplained variation, but the quadratic models for 2013, 2011 \& 2010 were higher than the linear model of 2012 growth (Figure 2).

\section{DISCUSSION}

The effects of herbivory on compensatory growth in woody plants have been heavily disputed. (Chira \& Kinyamario, 2009; Dublin et al., 1990; Jachmann \& Bell, 1985; Pellew, 1984; Smallie \& O'Connor, 2000). It is clear that elephant herbivory can drive vegetation change in savanna ecosystems, and dense elephant populations can sometimes lead to over-browsing and significant plant mortality (Van Aarde \& Guldemond, 2008).

Soil moisture and available nutrients are major confounding factors influencing Acacia growth (Mopipi et al., 2009). To reduce these variations, we measured trees only on mesic sites, i.e. sites with moderate and consistent soil moisture levels and nutrient availability in the context of the larger study area. Trees less than $200 \mathrm{~m}$ from roads were excluded to limit the impact of dust from nearby vehicle traffic. We excluded immature trees (DBH $<10 \mathrm{~cm})$ since differences in plant developmental stages have been shown to influence Acacia browsing response (Bergstrom, 1992). Trees shorter than $5 \mathrm{~m}$ were also excluded because they are more likely to be affected by the browsing of smaller mammals, which reduces Acacia growth due to the differences in browsing behavior of smaller browsers compared to elephants (Augustine, McNaughton \& Samuel, 2004). Although Dharani et al. (2008) showed that rainfall plays a significant role in Acacia growth, levels of 
precipitation were not a major confounding factor in this study since sites were within about $20 \mathrm{~km}$ of each other. Ben-Shahar (1996) also showed that fire and burn damage can significantly influence Acacia growth, but there was no recent history of fire in these areas (Tarangire, 2012), nor did we observe evidence of recent fires.

The three mesic sites used in this study were chosen to control for proximity to roads, tree maturity, and small mammal browsing; factors known to affect browsing response. The repeated measures ANOVA showed no significant difference between twig elongation across the three mesic sites $(p=.52)$, which indicates that location does not explain the observed variations (Table 1) and growth across sites can be regarded as the approximately the same.

Table 1. Repeated Measures ANOVA. The Summary table shows the effect of mesic site and year on annual growth (shoot elongation) in $A$. tortilis. Significant relationships were found ( $\mathrm{p}$-value $<0.05$ indicated by * symbol) between above ground growth and mesic site, as well for the interaction of site and growth year on growth. Model $R^{2}$ (adj.) $=0.46$ which indicates relatively high model performance.

\begin{tabular}{|l|l|l|l|l|l|}
\hline Term & df & Adj. SS & Adj. MS & $\boldsymbol{F}$-value & $\boldsymbol{p}$-value \\
\hline Site & 2 & 31.92 & 15.96 & 0.71 & 0.52 \\
\hline Year & 3 & 137.23 & 45.74 & 2.35 & 0.17 \\
\hline Tree (site) & 46 & 471.03 & 10.24 & 1.51 & $0.04^{*}$ \\
\hline Site* year & 6 & 116.69 & 19.45 & 2.86 & $0.01^{*}$ \\
\hline Error & 130 & 883.99 & 6.80 & & \\
\hline
\end{tabular}
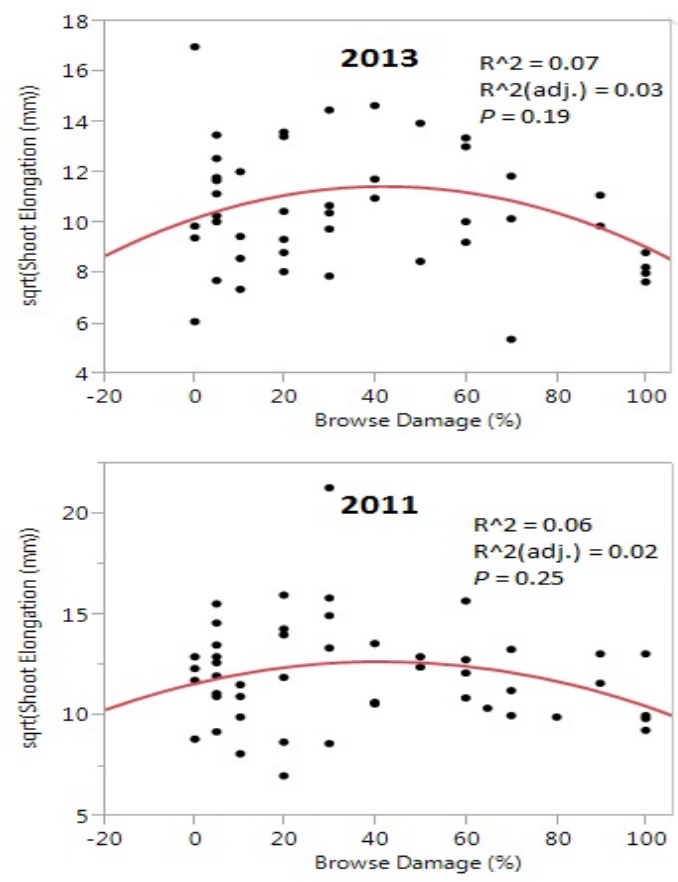

Annual variation in precipitation has been shown to be a significant driver of overall Acacia productivity (Mopipi et al., 2009; Otieno et al., 2001). However, in this study, tree measurements were taken for each of the last four years individually to control for variations in annual environmental conditions, such as drought, that might affect tree growth. There was no significant difference between twig elongation across years $(p=.17)$ (Table 1$)$. Thus, growth year did not explain the observed variations in twig elongation, and trees grew similar amounts across the four years. This is in line with Hayward \& Zawadska (2010), who found that precipitation variables had less of an impact on above ground growth than elephant browsing.

Recent studies have found evidence that intense large herbivore browsing can sometimes result in compensatory aboveground plant growth (Dublin et al., 1990; Jachmann \& Bell, 1985; Smallie \& O'Connor, 2000), while at other times having a negative effect on woody vegetation growth (Chira \& Kinyamario, 2009; Gulemond \& Aarde, 2008; Pellew, 1984). In this study A. tortilis shoot elongation varied little across the very broad continuum of browsing pressure (Figure 2), and browsing pressure explained little of variations in growth $\left(R^{2}=.07\right)$. Thus we conclude that, in terms of aboveground shoot elongation, the Tarangire National Park population tolerates elephant browsing remarkably well. This may help explain the dominance of $A$. tortilis in the park and other East African savanna ecosystems.

Our data show equivocal results on whether moderate levels of elephant browsing stimulate compensatory growth. Insig-
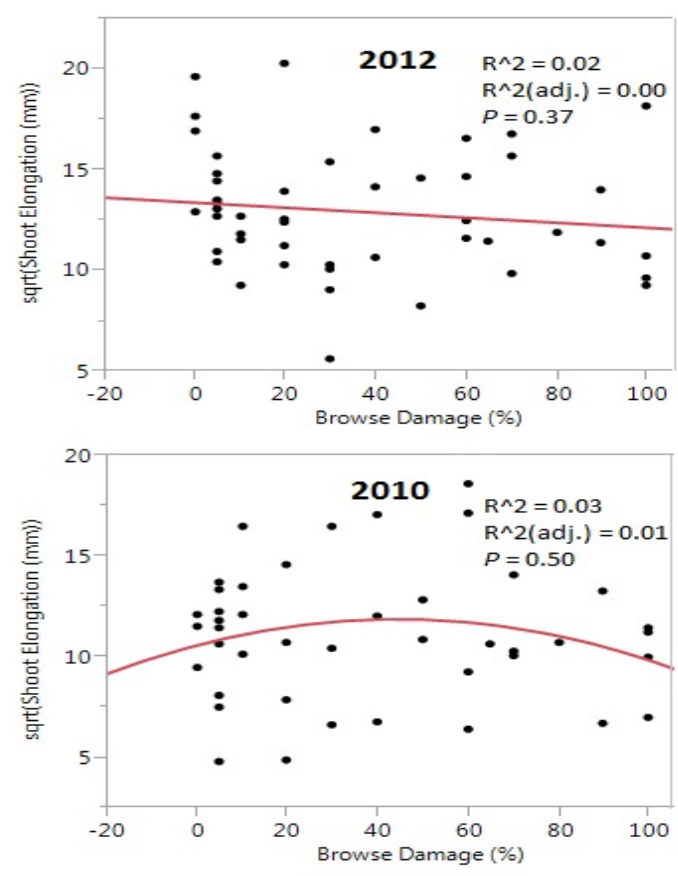

Figure 2. Effects of elephant browsing on $\boldsymbol{A}$. tortilis growth by year. Best fit regression models (linear or quadratic) represent the relationship between above ground growth (included as square root transformed shoot elongation) and elephant browsing (measured as percent of canopy damaged by increments of 10) of $A$. tortilis over four years $(2010,2011,2012 \& 2013)$. Each point is the mean growth measurement taken from four to five shoots from one tree. 
nificant trends in 2013, 2011 and 2010 (Figure 2) suggest support for the hypothesis and the conclusions of Du Toit et al. (1990), Chira \& Kinyamario (2009), and Stuart-Hill \& Tainton (1989) that compensatory growth occurs. The slight, insignificant decrease in 2012 shoot elongation as browsing increases (Figure 2) suggests support for the conclusions of Dharani et al. (2009) and Fornara (2008) that compensatory growth does not occur and that all levels of elephant browsing have a negative effect on above-ground growth. However, in contrast to these studies cited above, our results for four years in northern Tarangire National Park indicate a striking robustness to elephant browsing in A. tortilis, since even trees with heavy browsing damage had approximately the same shoot growth as trees with light or no browsing damage.

It is important to note that a large proportion of above ground growth variation among trees within sites remain unexplained by elephant browsing damage (Table 1). Substantial genetic differences, small-scale variation in soil nutrients and other soil properties, differences in above- and below-ground competition, time of elephant damage, and other environmental factors likely account for differences in shoot growth among replicate trees. This large variation will tend to mask patterns in growth with browse damage. Also, since important influences on growth such as fire, water, and nutrient availability will vary at other sites, resistance to browsing at other sites could show different patterns.

The variation in Acacia growth response to herbivory studied over the last 20 years, as well as within this paper, means that a unified understanding of Acacia compensatory growth remains elusive. Future studies might attempt to measure multiple responses, e.g., shoot elongation, the radial increment of trunks, reproduction, concentration of secondary compounds, and belowground growth in order to better understand this phenomenon. Since responses likely vary with water availability, studies across a water availability gradient and across years of varying precipitation might prove fruitful. Additionally, genetic variation within $A$. tortilis, seasonal timing of elephant browsing, previous elephant browsing, effects of other herbivores, and time since the last fire may also influence responses to elephant browsing. Future studies should also consider tree mortality and seedling establishment since growth measurements do not take mortality into account.

\section{CONCLUSION}

Based on shoot elongation data from four years, A. tortilis in northern Tarangire National Park appears to be tolerating browsing of the large elephant population well, with some insignificant suggestion of modest compensatory growth at moderate browsing levels. In one particular year, a slight decline in shoot growth in trees with heavier browsing is observed. Such an anomalous reverse in growth trends in this year could be evidence of herbivory tipping point, rather than the linear relationship suggested in other years, after which browsing is harming not stimulating above ground growth for $A$. tortilis. Since this tree species comprises such a large proportion of tree cover in the Park (Tanzania National Parks, 2012) and because the recent trend in elephant numbers is upward (Foley, 2010), we suggest like Gandiwa et al. (2011) in Zimbabwe, that Park managers should monitor growth responses and mortality of $A$. tortilis to ensure the vitality of this keystone species.

\section{ACKNOWLEDGEMENTS}

Thanks to my fellow students, Heather Hagerling, Nikki Hernandez, Mark Parlier, and Maxine Quinney, who suffered many an Acacia wound during the blistering late mornings of data collection. And thanks to our wonderful driver Walter Humphreys for navigating us daily throughout Tarangire National Park.

\section{REFERENCES}

Augustine, J., McNaughton, D., \& Samuel, J. (2004). Regulation of shrub dynamics by native browsing ungulates on east African rangeland. Journal of Applied Ecology, 41(1), 45-58.

Ben-Shahar, R. (1996). Woodland dynamics under the influence of elephant and fire in northern Botswana. Vegetation, 123(2), 153-163.

Bergström, R. (1992). Browse characteristics and impact of browsing on trees and shrubs in African savannas. Journal of Vegetation Science, 3(3), 315-324.

Chira, R. M., \& Kinyamario, J. I. (2009). Growth response of woody species to elephant foraging in Mwea National Reserve, Kenya. African Journal of Ecology, 47(4), 598-605.

Chung, K. Y., Wong, T. Y., Wei, C. I., Huang, Y. W. \& Lin, Y. (1998). Tannins and human health: a review. Critical Review of Food Science Nutrition, 38(6), 421-64.

Dharani, N., Kinyamario, J. I., Wagacha, P. W. \& Rodrigues, A. J. (2009). Browsing impact of large herbivores on Acacia xanthophloea in Lake Nakuru National Park, Kenya. African Journal of Ecology, 47(2), 184-191.

Dublin, H. T., Sinclair, A. R. E., \& McGlade, J. (1990). Elephant and fire as causes of multiple stable states in the Serengeti-Mara woodlands. Journal of Animal Ecology, 59, 1147-1164.

Du Toit, J. T., Bryant, J. P, \& Frisby, K. (1990). Regrowth and palatability of Acacia shoots following pruning by African savanna browsers. Ecology, 71(1), $149-153$.

Foley, C. A. H., \& Faust, L. J. (2010). Rapid population growth in an elephant Loxodonta africana population recovering from poaching in Tarangire National Park, Tanzania. Oryx, 44(2), 205-212.

Fornara, D.A., \& du Toit, J.T. (2007). Browsing lawns responses of Acacia nigrescens to ungulate browsing in an African savanna. Ecology, 88(1), 200.

Fornara, D.A., \& du Toit, J.T. (2008). Responses of woody saplings exposed to chronic mammalian herbivory in an African savanna. Ecoscience, 15(1), 129-135.

Gandiwa, E., Magwati, T., Zisadza, P., Chinuwo, T., \& Tafangenyasha, C. (2011). The impact of African elephants on Acacia tortilis woodland in northern Gonarezhou National Park, Zimbabwe. Journal of Arid Environments, 75(9), 809-814.

Guldemond, R., \& Van Aarde, R. (2008). A meta-analysis of the impact of African elephants on savanna vegetation. Wild Journal of Wildlife Management, 72(4), 892-899.

Hayward, M. W., \& Zawadzka, B. (2010). Increasing elephant Loxodonta africana density is a more important driver of change in vegetation condition than rainfall. Acta Theriologica, 55, 289-299.

Jachmann, H., \& Bell, R. H. V. (1985). Utilization by elephant of the Brachystegia woodland of the Kasungu National Park, Malawi. African Journal of Ecology, 23, 245-258.

JMP®, Version 11. SAS Institute Inc. 1989-2007. [Computer software] Cary, NC.

Ludwig, F., De Kroon, H. \& Prins, H. H. T.(2008). Impacts of savanna trees on forage quality for a large African herbivore. Oecologia, 155(3), 487-496.

McNaughton, S.J. (1979). Three grassland-herbivore dynamics. In: Serengeti, Dynamics of and Ecosystem. The University of Chicago Press, Chicago pp. 46-80.

Minitab. 17 Statistical Software. 2010. [Computer software]. State College, PA: 
Minitab, Inc. www.minitab.com.

Moncrieff, G. R., Chamaille-Jammes, S., Higgins, S. I., O’Hara, R. B., \& Bond, W. J. (2011). Tree allometries reflect a lifetime of herbivory in an African savanna. Ecology, 92(12), 2310-2315.

Mopipi, K., Trollope, S. W. W \& Scogings, P. F. (2009). Effects of moisture, nitrogen, grass competition and simulated browsing on the survival and growth of Acacia karroo seedlings. African Journal of Ecology, 47(4), 680-687.

Otieno, D. O., Kinyamario, J. I., \& Omenda, T. O. (2001). Growth features of Acacia tortilis and Acacia xanthophloea seedlings and their response to cyclic soil drought stress. African Journal of Ecology, 39(2), 126-132.

Owen-Smith, N. (1982). Factors influencing the consumption of plant products by large herbivores. In: B. J. Huntley \& B. H. Walker (Eds.), Ecology of tropical savannas (359-404). New York: Springer Berlin Heidelberg.

Pellew, R. A. (1984). The feeding ecology of a selective browser, the giraffe (Giraffa camelopardalis tippelskirchi). Journal of Zoology, 202, 57-81.

Riginos, C., \& Young, T. P. (2007). Positive and negative effects of grass, cattle, and wold herbivores on Acacia saplings in an East African savanna. Oecologia, 153(4), 985-995.

Scogings, P.F., Johansson, T., Hjalten, J., \& Kruger, J. (2012). Responses of woody vegetation to exclusion of large herbivores in semi-arid savannas. Australia Ecology, 37(1), 56-66.

Smallie, J. J., \& O'connor, T. G. (2000). Elephant utilization of Colophospermum mopane: possible benefits of hedging. African Journal of Ecology, 38, 352359.

Stuart-Hill, G. C., \& Tainton, N. M. (1989). The competitive interaction between Acacia karroo and the herbaceous layer and how this is influenced by defoliation. Journal of Ecology, 26, 285-298.

Tanentzap, A. J., \& Coomes D. A. (2012). Carbon storage in terrestrial ecosystems: do browsing and grazing herbivores matter. Biological Reviews of the Cambridge Philosophical Society, 87(1), 72-94.

Tanzania National Parks. (2012). Tarangire National Park. Retrieved September 10, 2014. http://www.tanzaniaparks.com. 